\title{
FOTO UDARA MENGGUNAKAN WAHANA UAV JENIS FIX WING
}

\author{
AERIAL PHOTOGRAPHY USING FIXED WING UAV \\ Oghy Octori ${ }^{1}$, Agung Budi Cahyono ${ }^{1}$ \\ ${ }^{1}$ Jurusan Teknik Geomatika - FTSP - Institut Teknologi Sepuluh Nopember \\ Email: oghyoctori92@gmail.com ${ }^{1}$, agungbc@geodesy.its.ac.id ${ }^{2}$
}

\begin{abstract}
Abstrak
Perkembangan teknologi yang semakin cepat dan kebutuhan masyarakat akan informasi spasial menjadi sebuah tantangan bagi para penyedia informasi spasial untuk mendapatkan informasi spasial secara cepat. Salah satu cara untuk mendapatkan informasi spasial adalah dengan foto udara dengan menggunakan pesawat tanpa awak atau UAV. Penelitian ini bertujuan untuk merakit sebuah wahana UAV dengan tipe fix wing dengan estimasi biaya yang murah dan memiliki kemampuan membuat peta foto udara. Peta foto udara yang di dapat dengan menggunakan wahana ini akan di proses dengan menggunakan metode fotogrametri. Dari hasil penilitian ini dihasilkan sebuah prototype UAV Fix Wing dengan total biaya perakitan sebesar Rp.12.850.000. UAV ini dapat melakukan foto udara sesuai dengan jalur terbang yang sudah di rencanakan dan menghasilkan sebuah peta foto. Hasil test terbang di daerah studi didapatkan Wahana yang dihasilkan yaitu Phantom FPV Flying Wing EPO yang didukung dengan Propeller 9x6 serta Turnigy $9 X R+$ Modul cukup stabil melakukan kegiatan pemotretan udara.
\end{abstract}

Kata kunci : UAV, tipe Fix Wing, Fotogrametri

\begin{abstract}
The development of increasing technology and spatial information will be a challenge for the providers of spatial information to obtain spatial information swiftly. One way to obtain spatial information is the aerial photograph using drones or UAVs. This study aims to build a vehicle with the type of fixed wing UAV with low cost and has the capability of aerial photographs. Photos are be taken using the UAV Flying Wing Himage 1 will be processed using photogrammetric method that result in the form of maps and have a spatial information. The results of this research produced a prototype of Fix Wing UAV that Flying Wing Himage 1 with autopilot capabilities with total assembly costs is Rp.12.850.000. This UAV can perform an aerial photographs according to the flight path that has been planned and produced a photo map. From flight test on 27 December 2014 in study area obtained RMSE that analyzed from ICP. The result on point $1(0,299 \mathrm{~m})$, point $2(0,729 \mathrm{~m})$, point $3(0,120 \mathrm{~m})$, and point $4(0,139 \mathrm{~m})$.
\end{abstract}

Keywords : UAV, Fix Wing, Photogrametry

\section{PENDAHULUAN}

\section{Latar Belakang}

Saat ini perkembangan teknologi semakin berkembang cepat dan semakin memudahkan manusia untuk mendapatkan informasi secara cepat, dan terpercaya. Kebutuhan untuk mendapatkan informasi secara cepat dan terpercaya menjadi sebuah tantangan yang harus diselesaikan, terutama dalam bidang pemetaan fotogrametri dalam mendapatkan informasi spasial berupa foto udara.
Salah satu cara untuk mendapatkan informasi spasial berupa foto udara adalah dengan menggunakan sebuah pesawat tanpa awak atau yang biasa disebut UAV (Unmanned Aerial Vehicle) fotogrametri. Dimana wahana yang dimaksud dapat mampu terbang sesuai perencanaan terbang (autopilot) dan dapat melakukan pemotretan foto udara.

Wahana yang dimaksud menggunakan pesawat tanpa awak atau disebut UAV (Unmanned Aerial Vehicle) yang merupakan wahana untuk pengambilan data foto udara yang selanjutnya 
akan diproses secara fotogrametri. UAV ini memungkinkan untuk melakukan pelacakan posisi dan orientasi dari sensor yang diimplementasikan dalam sistem lokal atau koordinat global (Eisenbeiss, 2008).

Pada penelitian ini, akan dilakukan perakitan sebuah wahana UAV jenis tipe Fix Wing yang dapat melakukan foto udara. Foto udara yang dimaksud adalah foto udara format kecil (FUFK) dengan menggunakan sebuah kamera non-metrik dengan panjang fokus $35 \mathrm{~mm}$. Lokasi uji terbang hasil penelitian dilakukan di kawasan perumahan Pakuwon City, Surabaya karena terdapat sebuah lapangan yang dapat di gunakan sebagai landasan terbang wahana UAV.

\section{METODOLOGI PENELITIAN}

\section{Data dan Peralatan}

- Data

1. Titik Kontrol Tanah dari hasil pengukuran GPS Geodetik.

2. Citra Google Earth Perumahan Pakuwon City.

\section{- Peralatan}

1. Phantom FPV Flying Wing EPO Airplane 1550mm (PNF) V2

2. Autopilot MyFlyDream

3. Canon IXUS $140 \mathrm{HS}$

4. Turnigy $9 x \mathrm{xr}$

5. Apm Planner 2.0

6. Komputer yang terdiri dari 1 buah Laptop dan 1 buah PC.

7. Perangkat aplikasi seperti : Software Permodelan 3D, CAD, Software Mission Planner

\section{Metode Penelitian Lokasi Penelitian}

Lokasi penelitian ini di lakukan di laboratorium HobbyTech serta test flight di daerah Perumahan Pakuwon City.

\section{Tahap Pengolahan Data}

Tahapan yang dilakukan dalam pengolahan data pada penelitian ini adalah :

1. Tahap Perakitan dan Uji Terbang

Pada tahap ini dilakukan perakitan dan uji terbang wahana UAV dengan membaca literatur, diskusi serta sharing dengan pakar serta grup aeromodeling.

2. Tahap Pengambilan Data

Pada tahap pengambilan data ini direncanakan dua kegiatan, yaitu:

a. Kalibrasi Kamera

Kegiatan ini dilakukan untuk mendapatkan data parameter kalibrasi kamera yang digunakan.

b. Pengukuran titik kontrol tanah dengan GPS Geodetik. Kegiatan ini dilakukan untuk mendapatkan data berupa GCP dan ICP.

c. Pemotretan Foto Udara

Kegiatan ini dilakukan dengan menerbangkan UAV sesuai dengan perencanaan jalur yang telah ditentukan, menentukan parameter ketinggian, jumlah foto, kecepatan serta timelaps kamera.

3. Tahap Pengolahan Data

Pada tahapan ini dilakukan pengolahan dari data berupa foto yang telah dihimpun untuk selanjutnya diproses menjadi peta foto.

4. Tahap Analisa dan Hasil

Tahap ini dilakukan untuk mengetahui, menganalisa dan mengevaluasi apakah wahana telah berjalan sesuai yang diinginkan serta seberapakah ketelitian hasil peta foto yang dihasilkan.

\section{HASIL DAN PEMBAHASAN}

\section{Tahap Kalibrasi Kamera}

Sebelum digunakan kamera yang digunkan perlu dikalibrasi. Kalibrasi kamera adalah proses menentukan Interior Orientation Parameter (IOP). Dari hasil kalibrasi kamera menggunakan perangkat lunak PhotoModeler 2013 dengan menggunakan jenis kamera Canon Ixus 140 HS dengan spesifikasi: panjang fokus $4 \mathrm{~mm}$, ukuran sensor $6.17 \times 4.55 \mathrm{~mm}$, tipe sensor BSI-CMOS, resolusi maksimal $4000 \times 3000$ piksel.

Tabel 1. Hasil Kalibrasi Kamera Canon Ixus 140 HS

\begin{tabular}{cl}
\hline Parameter & \multicolumn{1}{c}{ Nilai } \\
\hline $\mathrm{f}$ & $5.150457 \mathrm{~mm}$ \\
x0 & $3.119608 \mathrm{~mm}$ \\
y0 & $2.382292 \mathrm{~mm}$ \\
K1 & 0.0009539 \\
K2 & -0.000005422 \\
\hline
\end{tabular}




\begin{tabular}{ll}
\hline K3 & 0.000 \\
P1 & -0.0007506 \\
P2 & 0.0007901 \\
\hline
\end{tabular}

\section{Tahap Perakitan Pesawat}

Perakitan wahana UAV Flying Wing Himage 1 membutuhkan waktu 3 bulan, mulai dari pemesanan komponen sampai selesai proses perakitan. Komponen dan harga barang yang di gunakan adalah sebagai berikut:

Tabel 2. Komponen UAV Flying Wing Himage 1

\begin{tabular}{ccl}
\hline Nama Barang & Jumlah & Harga \\
\hline $\begin{array}{c}\text { Phantom FPV Flying Wing } \\
\text { EPO Airplane 1550mm }\end{array}$ & 1 & Rp. 1.500 .000 \\
Autopilot MyFlyDream & 1 & Rp. 3.500 .000 \\
Turnigy 9 XR + Modul & 1 & Rp. 1.800 .000 \\
Lipo Tx & 1 & Rp. 250.000 \\
Esc 40 Amper & 1 & Rp. 475.000 \\
Propeller 9x6 & 1 & Rp. 50.000 \\
Landing Gear & 1 & Rp. 150.000 \\
Nose Gear & 1 & Rp. 200.000 \\
Telemetry & 1 & Rp. 850.000 \\
Baterai Lippo 4s 2800 & 2 & Rp. 1.000 .000 \\
Charger B6 ACDC & 1 & Rp. 775.000 \\
Kamera Canon Ixus 140 HS & 1 & Rp. 1.600 .000 \\
Canon Remote Switch & 1 & Rp. 300.000 \\
Hobbytec 900 ky 400 watt & 1 & Rp. 400.000 \\
Total & & Rp. 12.850 .000 \\
\hline
\end{tabular}

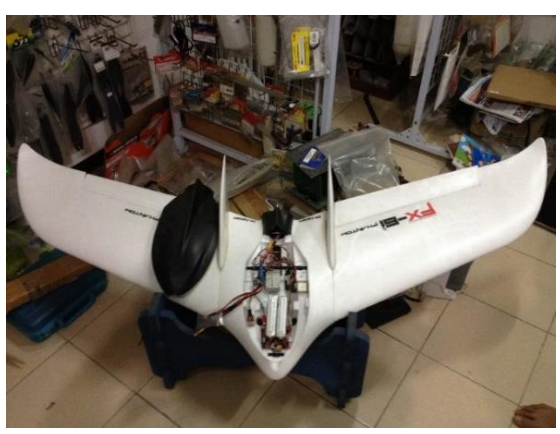

Gambar 3. Hasil perakitan UAV Flying Wing Himage 1

\section{Tahap Pembuatan Jalur Terbang}

Pembuatan jalur terbang adalah proses merencanakan jalur terbang untuk mendapatkan foto yang diinginkan dari foto udara. Pembuatan jalur terbang menggunakan perangkat lunak
Mission Planner yang sudah terhubung dengan autopilot.

$\begin{array}{ll}\text { Luas Area } & : 100.054 \mathrm{~m}^{2} \\ \text { Tinggi Terbang } & : 135 \mathrm{~m} \\ \text { Overlap } & : 70 \% \\ \text { Sidelap } & : 20 \% \\ \text { Jarak Antar Garis } & : 98.28 \mathrm{~m} \\ \text { Pengambilan Photo } & : 3 \mathrm{~second} / \text { Photo } \\ \text { Kecepatan Pesawat } & : 13 \mathrm{~m} / \mathrm{s} \\ \text { Jumlah foto } & : 42\end{array}$

Dimana jumlah 42 foto diatas adalah perkiraan hasil aplikasi Mission Planner dengan 2 jalur terbang.

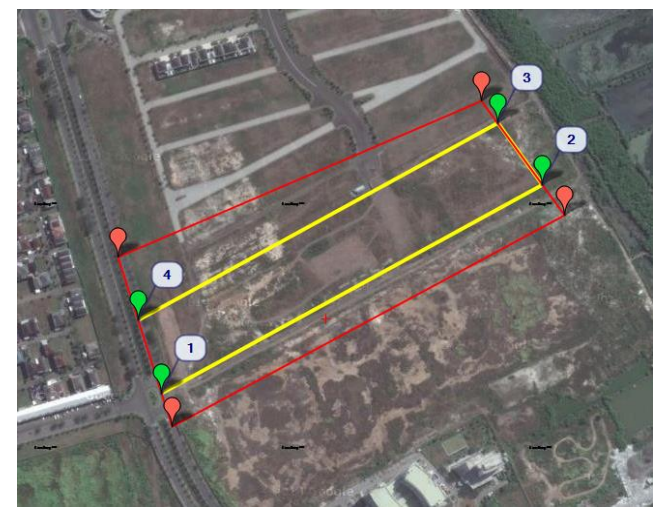

Gambar 4. Jalur Terbang UAV Flying Wing Himage-1

\section{Tahap Pengambilan Data GPS}

Pengambilan data kordinat yang diperuntukan untuk GCP foto dan titik kontrol pengukuran teristrial menggunakan alat gps Geodetik dan RTK (Real Time Kinematik) dengan menggunakan metode absolut. Terdapat 3 GCP dan 4 ICP.

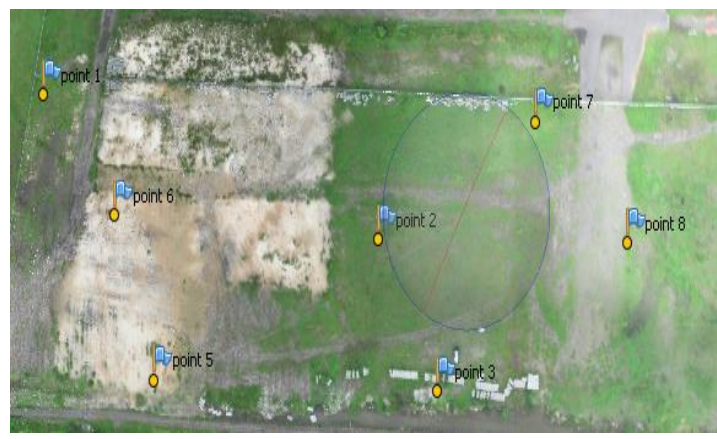

Gambar 5. Titik GCP dan ICP

Titik GCP dan ICP hasil pengukuran GPS tertera pada tabel dibawah ini :

Tabel 3. Koordinat GCP

\begin{tabular}{lll}
\hline GCP & $X(\mathrm{~m})$ & $Y(\mathrm{~m})$ \\
\hline Point 1 & 699742.416000 & 9196248.797000 \\
\hline
\end{tabular}




\begin{tabular}{lll}
\hline Point 5 & 699842.035000 & 9196189.720000 \\
Point 8 & 700021.428000 & 9196350.107000 \\
\hline
\end{tabular}

Tabel 4. Koordinat ICP

\begin{tabular}{lll}
\hline$I C P$ & $X(m)$ & $Y(m)$ \\
\hline Point 2 & 699915.164000 & 9196290.228000 \\
\hline Point 3 & 699967.392000 & 9196258.912000 \\
Point 6 & 699795.783000 & 9196230.409000 \\
Point 7 & 699961.707000 & 9196364.343000 \\
\hline
\end{tabular}

\section{Hasil Foto Udara}

Dari hasil pemotretan dengan di dapatkan foto sebanyak 65 foto. Hal ini berbeda dengan perkirakan karena autopilot belum bekerja dengan baik, sehingga jalur terbang serta tinggi terbang tidak sesuai dengan yang direncanakan. Hasil tsb kemudian di olah dengan menggunakan perangkat lunak Permodelan $3 D$ sehingga menghasilkan sebuah mosaik foto pada gambar di bawah ini.
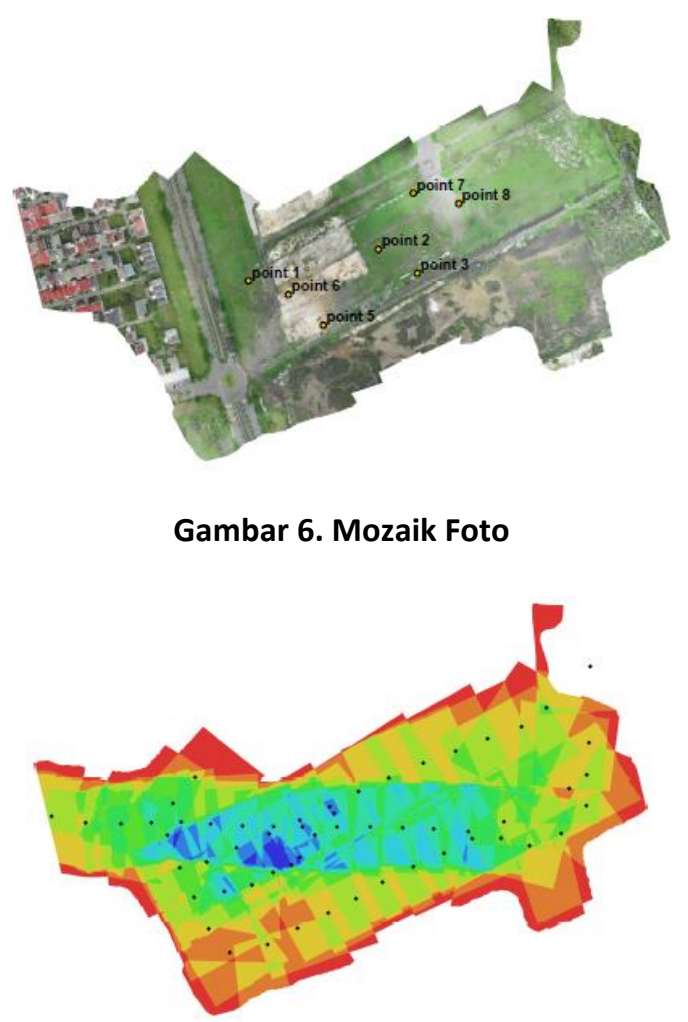

Gambar 7. Posisi pesawat saat pengambilan foto

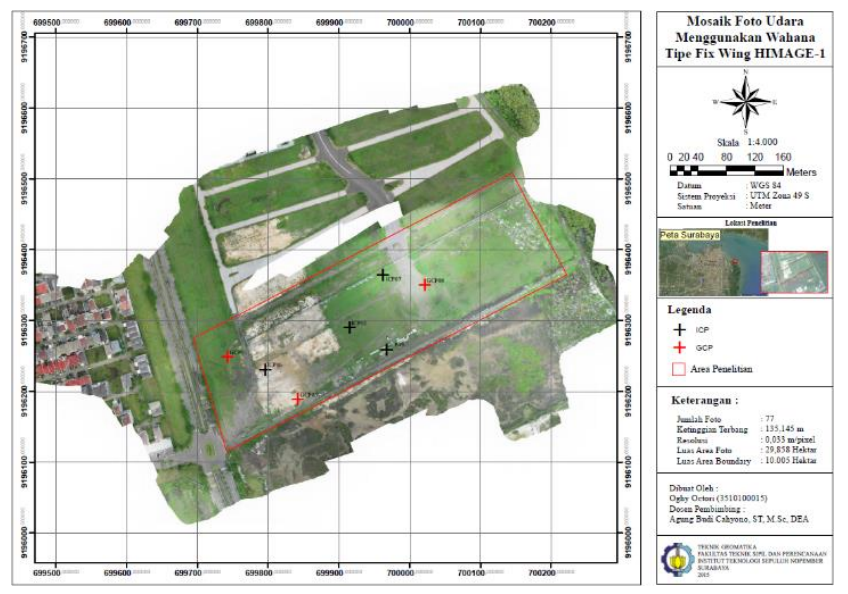

Gambar 8. Hasil Peta Foto

\section{Analisa}

Dari hasil terbang wahana Phantom FPV Flying Wing EPO yang didukung dengan Propeller 9x6 serta Turnigy 9 XR + Modul cukup stabil melakukan penerbangan.

Penggunaan Autopilot MyFlyDream masih perlu dipelajari lebih lanjut hal ini dikarenkan beberapa kali mengalami lost-control yuang menyebabkan wahana keluar dari jalur terbang.

Dan dari hasil mosaik foto tersebut dapat di analisa tingkat ketelitian koordinat GCP dan ICP seperti pada tabel di bawah.

Tabel 5. Analisa RMSE

\begin{tabular}{cccc}
\hline \multirow{2}{*}{ Titik } & \multicolumn{2}{c}{ Residu } & RMSE \\
& Easting & Northing & \\
\hline ICP 2 & 699915,164 & 9196290,228 & 0,299 \\
ICP 3 & 699967,392 & 9196258,912 & 0,729 \\
ICP 6 & 699795,783 & 9196230,409 & 0,120 \\
ICP 7 & 699961,707 & 9196364,343 & 0,139 \\
\hline
\end{tabular}

\section{PENUTUP}

\section{Kesimpulan}

Kesimpulan dari hasil penelitian ini adalah :

1. Telah berhasil dirakit sebuah prototype UAV bertipe Fixed Wing dengan spesifikasi lebar sayap 1,550m, dan kemampuan autopilot yang mampu terbang selama 20 menit dengan maksimal interval pengambilan foto $3 \mathrm{~s} /$ foto dengan perkiraan biaya sebesar +/- Rp. 12.850 .000 .

2. Wahana yang dihasilkan yaitu Phantom FPV Flying Wing EPO yang didukung dengan Propeller 9x6 serta Turnigy 9 XR + Modul 
cukup stabil melakukan penerbangan. Dimana Autopilot MyFlyDream masih perlu dipelajari lebih lanjut hal ini dikarenakan beberapa kali mengalami lost-control yuang menyebabkan wahana keluar dari jalur terbang sehingga hasil foto lebih banyak daripada jumlah foto pada saat perencanaan.

3. UAV dengan tipe Fixed Wing yang dihasilkan dalam uji coba tahap awal ini mampu melakukan pemotretan udara dengan RMSE ICP rerata 0,5 meter.

\section{Saran}

Diperlukan studi lanjut tentang uji coba lebih dengan parameter seperti tinggi terbang yang berbeda, ketahanan baterai serta kekuatan sinyal transmitter untuk bisa menghasilkan cakupan peta yang lebih luas.

\section{UCAPAN TERIMA KASIH}

Penulis mengucapkan terima kasih kepada Hobbytech Surabaya dan tim Aeromodeling Pakuwon yang telah bersedia memberikan dukungan alat serta memberikan saran dan informasi selama perakitan wahana UAV Flying

\section{Wing Himage 1.}

\section{DAFTAR PUSTAKA}

Eisenbeiss, H, 2009. UAV Photogrammetry. Zürich. ETH Zürich.

Hobbytech Surabaya, 2014. Perakitan Pesawat. www.hobbytecmodel.com/. Surabaya.

Manual, 2009. RTF Phantom FX-61. http://www.hobbytech.com.my/. 